\title{
Numerical Modeling of Temperature Distributions within the Neonatal Head
}

\author{
GERARD M. J. VAN LEEUWEN, JEFF W. HAND, JAN J.W. LAGENDIJK, DENIS V. AZZOPARDI, \\ AND A. DAVID EDWARDS \\ Radiological Sciences Unit [G.M.J.V.L., J.W.H.], Department of Imaging, Imperial College School of \\ Medicine, Hammersmith Campus, London W12 OHS, U.K; Department of Radiotherapy [J.J.W.L.], \\ Medical Center Utrecht, 3584 CX Utrecht, The Netherlands; and Department of Paediatrics [D.V.A., \\ A.D.E.], Imperial College School of Medicine, Hammersmith Campus, London W12 0HS, U.K.
}

\begin{abstract}
ABST
Introduction of hypothermia therapy as a neuroprotection ther-
apy after hypoxia-ischemia in newborn infants requires appraisal of
cooling methods. In this numerical study thermal simulations were
performed to test the hypothesis that cooling of the surface of the
cranium by the application of a cooling bonnet significantly reduces
deep brain temperature and produces a temperature differential
between the deep brain and the body core. A realistic three-
dimensional (3-D) computer model of infant head anatomy was
used, derived from magnetic resonance data from a newborn infant.
Temperature distributions were calculated using the Pennes heatsink
model. The cooling bonnet was at a constant temperature of $10^{\circ} \mathrm{C}$.
When modeling head cooling only, a constant body core tempera-
ture of $37^{\circ} \mathrm{C}$ was imposed. The computed result showed no signif-
icant cooling of the deep brain regions, only the very superficial
regions of the brain are cooled to temperatures of $33-34^{\circ} \mathrm{C}$. Poor
\end{abstract}
Studies of experimental cerebral injury have shown that promoting or allowing moderate cooling of the brain after hypoxia-ischemia can reduce damage and improve functional outcome (1-3). The mechanism of neuroprotection is unclear, but mild hypothermia reduces the fall in $[\mathrm{PCr}] /[\mathrm{Pi}]$ seen during delayed injury in immature piglets and rats (3), suppresses the development of delayed cytotoxic edema in fetal sheep (4), reduces extracellular concentrations of excitatory amino acids (5), and reduces the number of cells with the characteristics of apoptosis in newborn piglets (6).

The simplicity and wide efficacy of hypothermic neural protection have already led to preliminary clinical trials of moderate cooling in newborn infants suffering perinatal asphyxia $(7,8)$. However there are few data available on temperature distribution within the newborn brain, or on the effect of either local or systemic cooling. These data are difficult to

Received January 10, 2000; accepted April 21, 2000.

Correspondence and reprint requests to: Dr. G. Van Leeuwen, Radiological Sciences Unit, Department of Imaging, Hammersmith Hospital, DuCane Road, London W12 0HS, U.K.

This work was supported in part by the UK Engineering and Physical Sciences Research Council (EPSRC), and the Garfield Weston Foundation. efficacy of head cooling was still found after a considerable increase in the modeled thermal conductivities of the skin and skull, or after a decrease in perfusion. The results for the heatsink thermal model of the infant head were confirmed by comparison of results computed for a scaled down adult head, using both the heatsink description and a discrete vessel thermal model with both anatomy and vasculature obtained from MR data. The results indicate that significant reduction in brain temperature will only be achieved if the infant's core temperature is lowered. (Pediatr Res 48: 351-356, 2000)
Abbreviations
CBF, cerebral blood flow
3-D, three-dimensional
MRI, magnetic resonance imaging

acquire, as accurate invasive measurements of newborn infant brain temperature cannot easily be justified, and animal models may be misleading due to differences in cerebral metabolism, blood flow, or geometry. Yet successful clinical application of brain cooling requires that, as with any other therapy, the distribution and dose are known. This is particularly important, as studies using magnetic resonance imaging (MRI) have demonstrated that in newborn infants the basal ganglia are significantly warmer than more superficial cerebral tissues (9, 10 ), and that injury to the deep brain structures predicts severe neurologic impairment while cortical injury is relatively benign (11).

The lack of basic data makes it unclear as to whether localized cooling of the head or systemic cooling of the whole body is the most appropriate approach for clinical neural rescue therapy. Although almost all animal studies have examined models in which the whole body is cooled, concerns to minimize potential toxicity have led some researchers to favor a local head cooling approach. However, until the temperature distribution can be predicted accurately, clinical trials are at risk of choosing suboptimal cooling strategies. We have there- 
fore taken advantage of advances in the numerical modeling of heat transport in tissues and used a computational approach to predict temperature distributions in the brain.

In this paper we test the clinically relevant hypothesis that: cooling of the surface of the cranium by the application of a cooling bonnet significantly reduces deep brain temperature and produces a temperature differential between the deep brain and core body temperatures. This was done by numerical simulation of the effect of a cooling cap using Pennes' heatsink model (12) in an anatomically realistic representation of an infant's head. Because of their likely significance, cerebral perfusion and thermal conductivity of the skull were then varied to test the stability of the results with respect to these parameter values. The solidity of the heatsink results was probed by repeating the heatsink base simulations using a reduced size adult head model, and comparing the results with those obtained for temperature simulations in which the heatsink model is discarded and the thermal effects of blood flow are modeled using detailed discrete vascular trees $(13,14)$.

\section{METHODS}

Anatomical and thermal models. Two distinct head models were derived from multisection magnetic resonance (MR) data that were reformatted to 3-D data sets and segmented according to tissue type. The primary model was derived from a T1-weighted data set obtained by MR imaging a newborn infant born at term. Permission to use MRI scans was granted by the Hammersmith Hospitals Research Ethics Committee. The eventual data set consisted of $155 \times 149 \times 109$ voxels of $(1 \mathrm{~mm})(3)$ and was segmented to muscle, bone, fat, CSF, eyes, and brain. We did not differentiate between white and gray matter. The values assumed for the thermal properties of the tissues are listed in Table 1. All temperature distributions in this infant head model were calculated using a heatsink thermal model. This model calculated a finite difference numerical solution to the equation

$$
\rho c \frac{d T}{d t}=\nabla(k \nabla T)+B+M
$$

where $\rho, c$, and $k$ are the density, specific heat, and thermal conductivity of the tissue, $T$ is the local temperature, and $t$ is the time. $M$ represents the power per unit volume arising from metabolic heat production. The heatsink term $B$ accounts for the loss/gain of energy per unit volume due to blood at core temperature equilibrating to the local tissue temperature and is given by

$$
B=-W_{\text {blood }} c_{\text {blood }}\left(T-T_{\text {core }}\right)
$$

where $W_{\text {blood }}$ is the volumetric perfusion rate, $c_{\text {blood }}$ is the specific heat of blood, and $T_{\text {core }}$ represents the core temperature. The value of $c_{\text {blood }}$ was assumed to be $3825 \mathrm{~J} \mathrm{~kg}^{-1} \mathrm{~K}^{-1}$. The value of $W_{\text {blood }}$ was assumed to be independent of temperature in each of the tissues. The air temperature was fixed at $32^{\circ} \mathrm{C}$ in the simulations, typical of that in an incubator, and the thermal conductivity of air was chosen such that, in effect, the heat transfer coefficient between skin surface and air was $8 \mathrm{~W}$ $\mathrm{K}^{-1} \mathrm{~m}^{-2}(15)$. The neck boundary was modeled as an isothermal boundary at the body core temperature.

The second realistic anatomical model was an 11/15 scaleddown segmented adult head, obtained in a similar way from $\mathrm{T}_{1}$-weighted MRI data (16). In addition, for this head model information on the corresponding cerebral vasculature was available from 3-D MR angiography (MRA). Using these data the discrete vasculature of the head was interactively built by tracing the visible vessels (down to approximately $0.7 \mathrm{~mm}$ diameter), as shown in Figure 1 $a$, and then smaller vessels were added using an automated vessel generation algorithm (17) to obtain a better description of heat transfer in the anatomy. The diameter of the smallest vessels in the final vascular structure, shown in Figure $1 b$ was $0.2 \mathrm{~mm}$. The DIVA (DIscrete VAsculature) thermal model $(18,19)$, developed for hyperthermia treatment planning, was used to calculate the temperature distributions. It was shown that by this model even vessels with diameters smaller than the tissue voxel size can be accurately modeled (20), thus enabling investigators to model the majority of the thermally significant vessels individually. This avoids having to make the harsh assumptions about the thermal influence of blood flow inherent in heatsink and rival continuum theories $(12,21)$.

Simulations of temperature distributions. The hypothesis was addressed by imposing a cooling bonnet over the head, as shown in Figure 2, and calculation of the stationary temperature distribution. To simulate the bonnet, a region around the head was assumed to contain water at a uniform and constant temperature of $10^{\circ} \mathrm{C}$. In the simulations of head cooling alone, the infant's core temperature, and hence the temperature of the blood supply to the head, was assumed to be $37^{\circ} \mathrm{C}$. Metabolic heat production was independent of temperature, and values for the tissues were roughly proportional to the perfusion. Changes in modeled cerebral blood flow (CBF) were accompanied by a corresponding change in metabolic heat rate.

Table 1. Base set of parameters used in heat sink thermal model

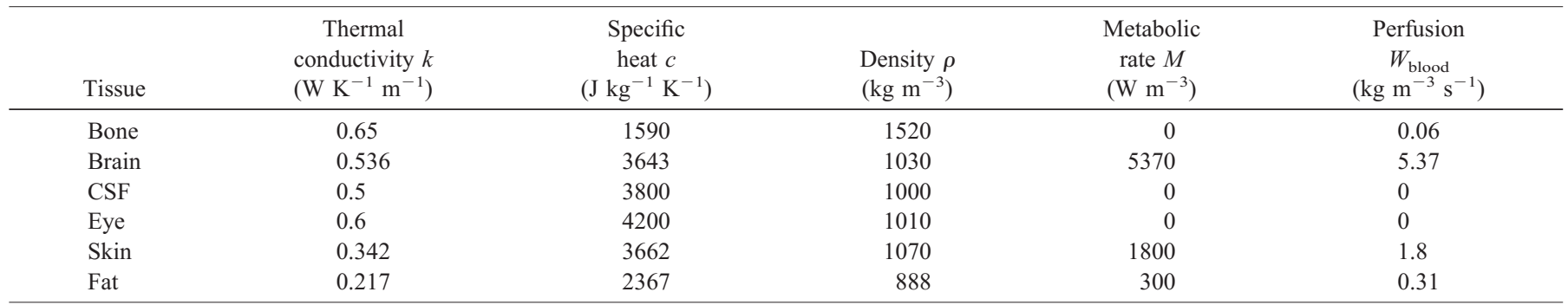


a

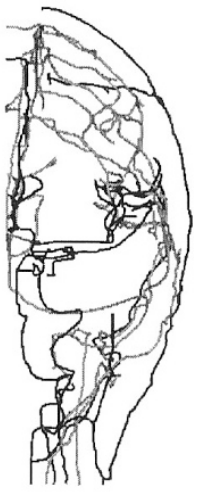

b

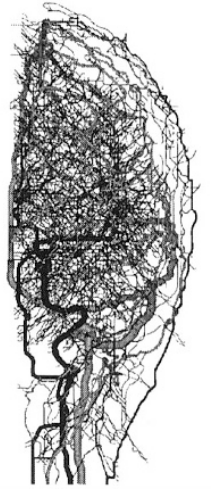

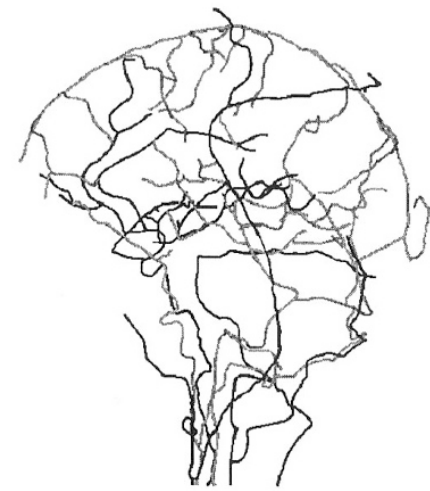

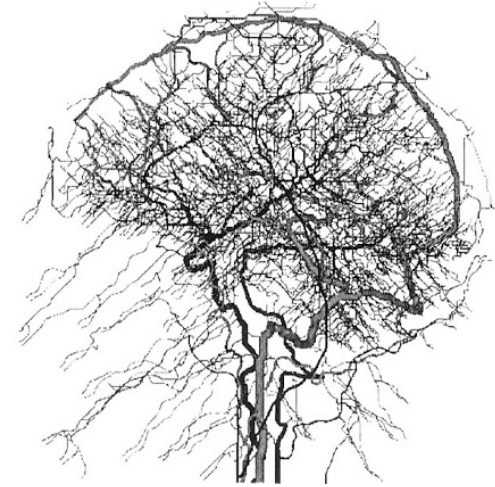

Figure 1. Discrete vessel structures, $(a)$ retrieved from magnetic resonance angiography, $(b)$ including vessels down to $0.2 \mathrm{~mm}$ diameter grown algorithmically. Two orthogonal views through the 3-D structures are shown for each case.

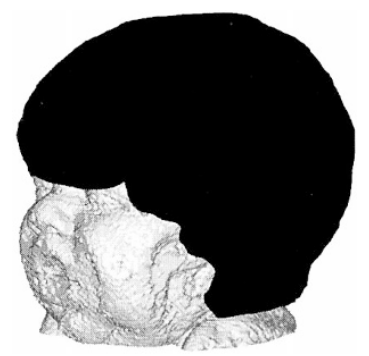

Figure 2. Model baby head reconstructed from MRI data with cooling bonnet.

To assess stability of the predictions with respect to changes in various model parameters, simulations featuring the following parameter value variations were carried out:

- $\mathrm{CBF}$ was increased from $30 \mathrm{~mL} \cdot \mathrm{min}^{-1} \cdot 100 \mathrm{~g}^{-1}$ to 40 $\mathrm{mL} \cdot \mathrm{min}^{-1} \cdot 100 \mathrm{~g}^{-1}$

- $\mathrm{CBF}$ was decreased from $30 \mathrm{~mL} \cdot \mathrm{min}^{-1} \cdot 100 \mathrm{~g}^{-1}$ to 15 $\mathrm{mL} \cdot \mathrm{min}^{-1} \cdot 100 \mathrm{~g}^{-1}$

- thermal conductivity of skin and bone were tripled compared with the values given in Table 1 . In these simulations CBF was $30 \mathrm{~mL} \cdot \mathrm{min}^{-1} \cdot 100 \mathrm{~g}^{-1}$.

Base conditions and parameters-head cooling, CBF 30 $\mathrm{mL} \cdot \mathrm{min}^{-1} \cdot 100 \mathrm{~g}^{-1}$, normal heat conduction - were also simulated in the reduced adult-head model, both using the heatsink model and using the discrete vessel thermal models.

Finally, the combination of head cooling and whole body cooling was simulated by repeating the simulation used to test

the hypothesis, but in addition, the infant's core temperature was set to the reduced level of $34^{\circ} \mathrm{C}$.

\section{RESULTS}

Figure 3 shows isosurfaces within the 3-D MR data set of the infant head (primary model) with the orthogonal sections on which the calculated temperature distributions are contoured as described below. Figure 4 shows temperature contours calculated for the case when the temperature of the water in the cooling bonnet was $10^{\circ} \mathrm{C}$ and the baby's core temperature was $37^{\circ} \mathrm{C}$. It can be seen that, far from causing significant cooling of the deep regions of the brain, a large temperature gradient is produced across the superficial tissues in the head and only the most superficial regions of the brain are cooled to temperatures of $33-34^{\circ} \mathrm{C}$. Indeed, due to the metabolic heat production, temperatures in much of the deep brain remain above set core temperature of $37^{\circ} \mathrm{C}$. Compared with a simulation in which the bonnet is modeled at $34^{\circ} \mathrm{C}$ (the "normal" skin temperature, so as to have no impact), the maximum temperature in the brain dropped only by one hundredth degree centigrade to $37.25^{\circ} \mathrm{C}$.

Considering only the temperatures along a mediolateral axis of the primary model enables a more detailed examination of the temperature distribution. Figure 5 shows the dependence of the predicted temperatures on simulated CBF. The effects of an increase in thermal conductivity of skin and skull (and therefore a decrease in thermal resistance) on this profile are shown in Fig. 6.

Figure 7 shows the sections in which the temperature distributions calculated within the reduced adult head are presented. The temperature distribution resulting from head cooling alone (water temperature $10^{\circ} \mathrm{C}$ ) predicted using the heatsink thermal model is shown in Figure 8 while that predicted by the discrete vessel model under the same cooling conditions is shown in Figure 9.

The temperature distribution predicted in the primary model for the case of head cooling (water at $10^{\circ} \mathrm{C}$ ) in combination with whole body cooling (infant's core temperature decreased to $34^{\circ} \mathrm{C}$ ) is shown in Figure 10 .

\section{DISCUSSION}

The results of our simulation using the primary baby-head model testify that the hypothesis "cooling of the surface of the cranium by the application of a cooling bonnet significantly reduces deep brain temperature and produces a temperature
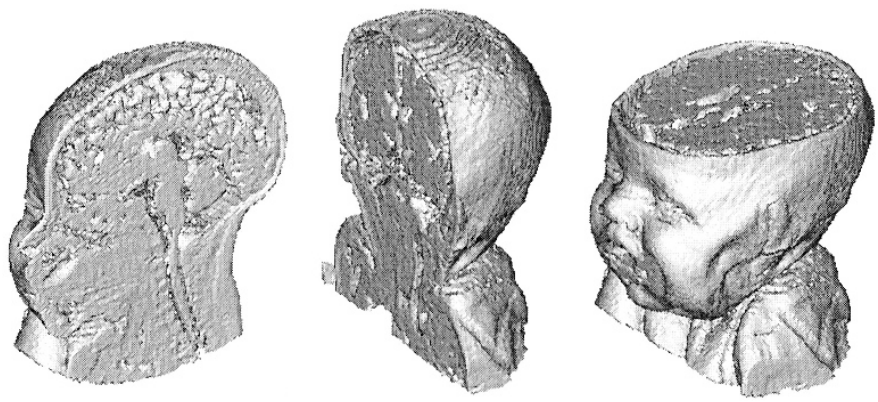

Figure 3. Orthogonal sections within the 3-D MRI data set of the baby head on which the calculated temperature distributions are presented. 


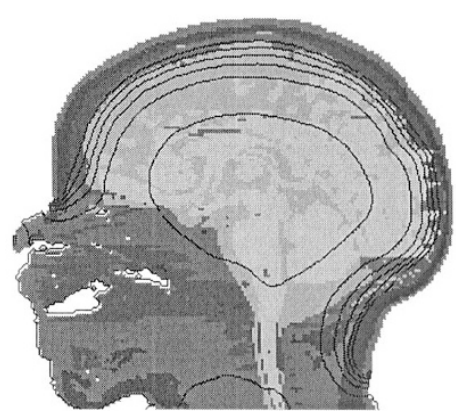

b

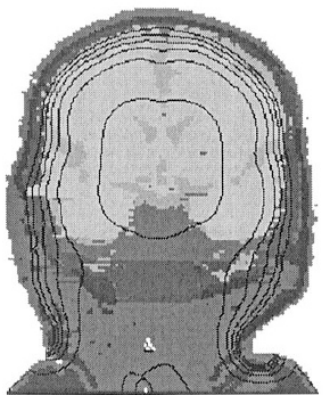

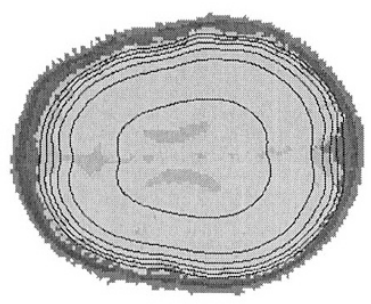

Figure 4. Predicted temperature distribution in the infant head displayed as contours on the sections depicted in Figure 3 . Water cap temperature $10^{\circ} \mathrm{C}$, infant's core temperature $37^{\circ} \mathrm{C}, \mathrm{CBF} 30 \mathrm{~mL} \cdot \mathrm{min}^{-1} \cdot 100 \mathrm{~g}^{-1}$. The maximum temperature predicted was $37.25^{\circ} \mathrm{C}$. Contours shown (from innermost outwards) are $37^{\circ}$, $35^{\circ}$, $33^{\circ}, 31^{\circ}, 29^{\circ}$, and $27^{\circ} \mathrm{C}$, respectively.

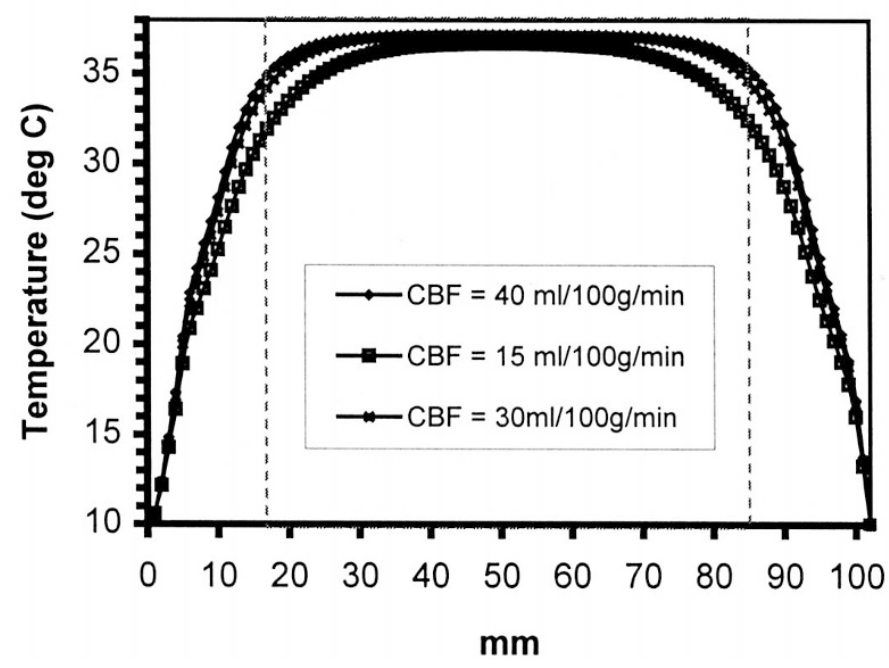

Figure 5. Dependence of predicted temperature profiles along the line $\mathrm{AB}$ in the axial section of the primary model shown on CBF. Dashed lines represent the inner boundary of the skull.

differential between the deep brain and core body temperature" is false. If the head is cooled while maintaining normal systemic temperature, the temperatures in deep brain structures remain far above the target temperature for mild hypothermia, as shown in Figures 4 and 5, and the temperature distribution induced is characterized by significant temperature gradients within the most superficial $20 \mathrm{~mm}$ of tissue.

The temperature profile within the head is dependent upon the values of the parameters used in equations 1 and 2. Figure 5 shows that increasing $\mathrm{CBF}$ from a normal value of 30

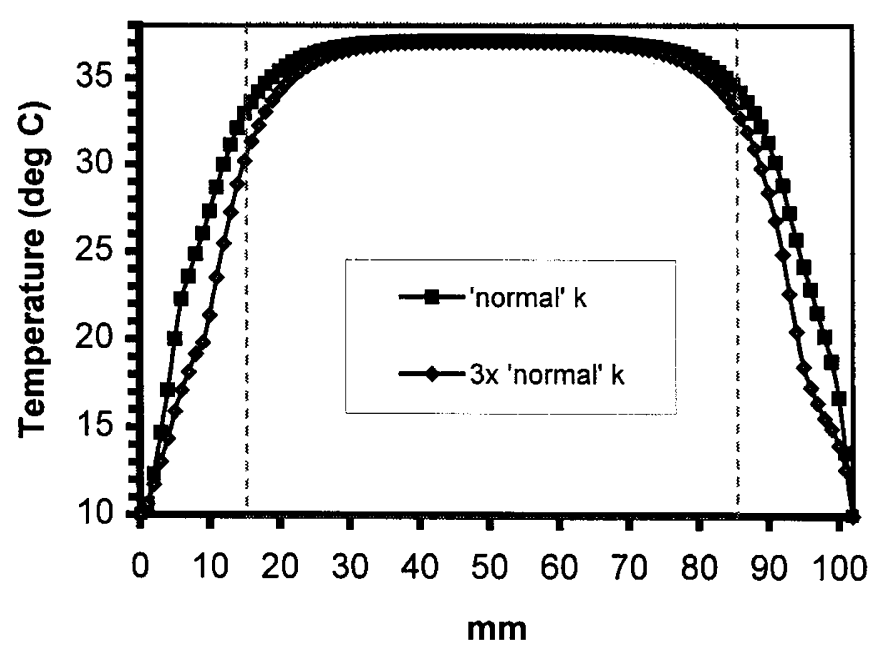

Figure 6. Dependence of predicted temperature profiles along the line $\mathrm{AB}$ in the axial section of the primary model shown in Figure 5 on thermal conductivities " $k$ " of skin, fat, and bone. The result of a 3 -fold increase in the three conductivities is compared with the "normal" curve. Dashed lines represent the inner boundary of the skull.
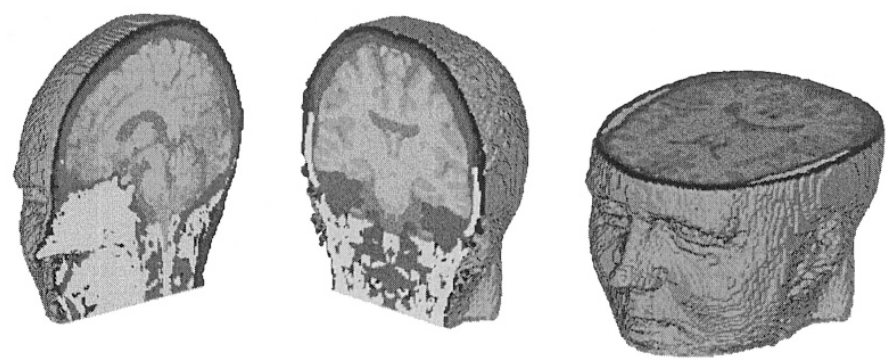

Figure 7. The orthogonal sections within the reduced adult head model, based on 3-D magnetic resonance imaging data, on which the calculated temperature distributions are presented.

$\mathrm{mL} \cdot \mathrm{min}^{-1} \cdot 100 \mathrm{~g}^{-1}$ to a value more representative of an infant who has suffered hypoxia-ischemia $\left(40 \mathrm{~mL} \cdot \mathrm{min}^{-1} \cdot 100 \mathrm{~g}^{-1}\right)$ results in essentially no change in the temperature of deep brain structures and a marginal increase in the temperature in superficial tissues, reducing slightly further the depth below the skin at which a significant decrease in temperature is achieved. It is only when CBF, instead of rising, falls significantly below the normal value (viz., a $50 \%$ decrease) that hypothermia is 

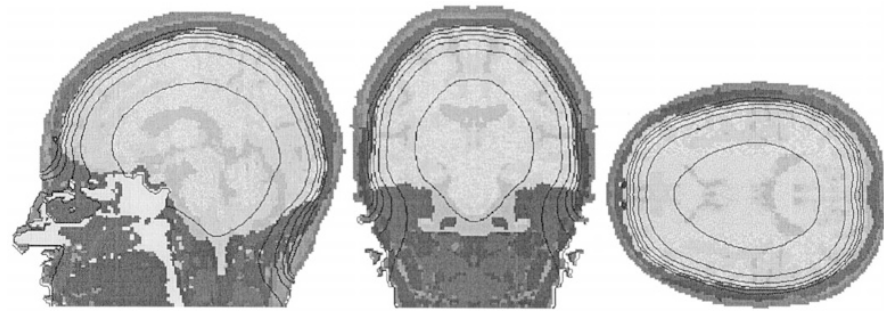

Figure 8. Predicted temperature distribution in the reduced adult head using the heatsink thermal model and displayed as contours on the sections depicted in Figure 7. Water cap temperature $10^{\circ} \mathrm{C}$, infant's core temperature $37^{\circ} \mathrm{C}, \mathrm{CBF}$ $30 \mathrm{~mL} \cdot \mathrm{min}^{-1} \cdot 100 \mathrm{~g}^{-1}$. The maximum temperature predicted was $37.24^{\circ} \mathrm{C}$. Contours shown (from innermost outwards) are $37^{\circ}, 35^{\circ}, 33^{\circ}, 31^{\circ}, 29^{\circ}$, and $27^{\circ} \mathrm{C}$, respectively.
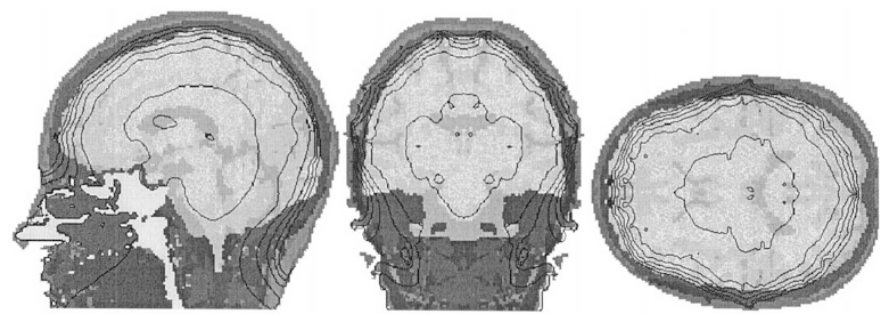

Figure 9. Predicted temperature distribution in the reduced adult head using the discrete vessel thermal model and displayed as contours on the sections depicted in Figure 7. Water cap temperature $10^{\circ} \mathrm{C}$, infant's core temperature $37^{\circ} \mathrm{C}, \mathrm{CBF} 30 \mathrm{~mL} \cdot \mathrm{min}^{-1} \cdot 100 \mathrm{~g}^{-1}$. The maximum temperature predicted was $37.20^{\circ} \mathrm{C}$. Contours shown (from innermost outwards) are $37^{\circ}, 35^{\circ}, 33^{\circ}, 31^{\circ}$, $29^{\circ}$, and $27^{\circ} \mathrm{C}$, respectively.

achieved in an appreciable part of the brain. However, in the deep brain the temperature still drops by no more than $0.5^{\circ} \mathrm{C}$, and now the most superficial brain is cooled as far down as $28^{\circ} \mathrm{C}$. The inefficiency of conductive trans-cranial cooling is also shown by modeling a large (3-fold) increase in the thermal conductivity values of skin, fat, and bone. The effect here, as shown in Figure 6, is a drop in temperature for the superficial layers, which however does not penetrate deeply in the brain. This result confirms that it is not the thermal resistance of the skull but the effect of brain perfusion that prevents good cooling. Similar results for the brain temperatures will be found for other changes in the modeled head that lead to a reduction of the thermal resistance, e.g. a thinner skin or skull.

The dependence of the predicted temperature distribution on the level of metabolism, all else being equal, is such that the difference between the maximum temperature and core temperature will scale linearly with metabolic rate. This follows from equations 1 and 2 and the observation that in the simulations the temperature gradient deep in the brain is very small so that the conductive term can be neglected. If this is done, application of above equations leads to a prediction of the temperature $0.26^{\circ} \mathrm{C}$ over core temperature. It is seen that this is close to simulated maximum temperatures (captions to Figs. 4 and $8-10$ ) showing that trans-cranial cooling fails to have a significant effect on deep brain temperatures. Because of the predictable influence of metabolism this parameter was not varied in the simulations.

Although the heatsink model has been used frequently to describe living tissue heat transfer, the approximations inherent in this approach have been questioned and other representa-

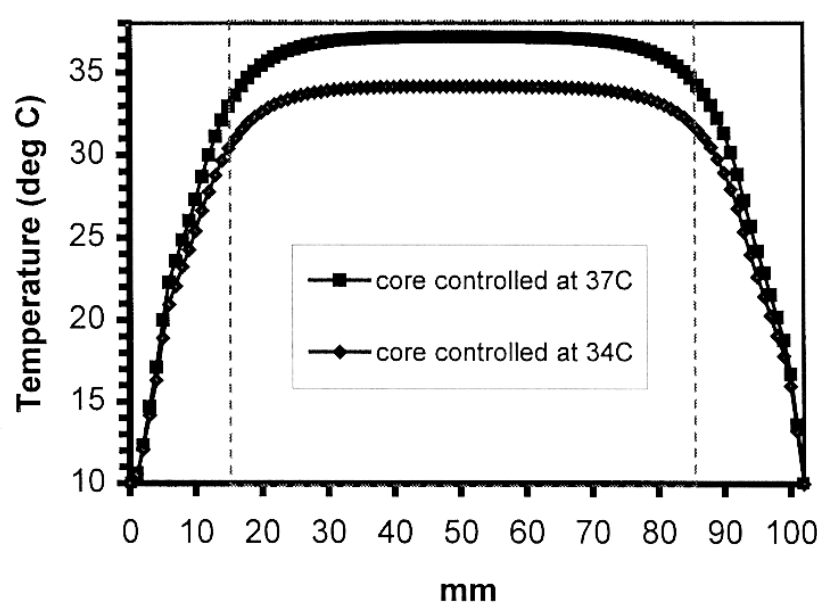

a

b

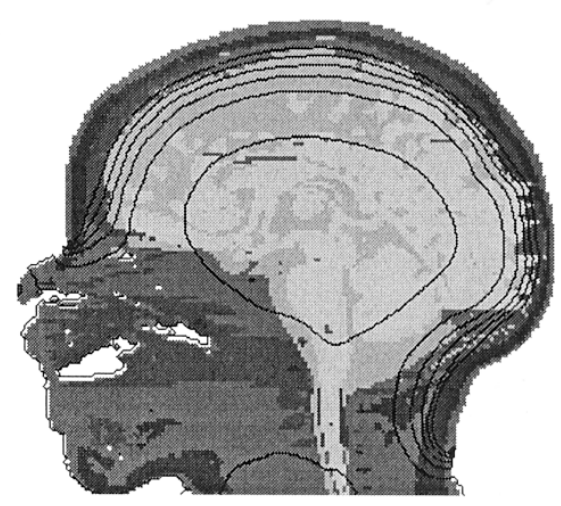

Figure 10. Predicted temperature distribution in the infant head (primary model) for simulated head and whole body cooling. Water cap temperature $10^{\circ} \mathrm{C}$, infant's core temperature $34^{\circ} \mathrm{C}, \mathrm{CBF} 30 \mathrm{~mL} \cdot \mathrm{min}^{-1} \cdot 100 \mathrm{~g}^{-1}$. The maximum temperature predicted was $34.25^{\circ} \mathrm{C}$. (a) Temperature profile along the line $\mathrm{AB}$ as in Fig. 5, as compared with head cooling only (b) Sagittal section with contours (from innermost outwards) at $34^{\circ}, 32^{\circ}, 30^{\circ}, 28^{\circ}, 26^{\circ}$, and $24^{\circ} \mathrm{C}$.

tions of heat transport have been proposed to model the collective thermal effects of the blood vessels (13). By use of both the heatsink model and a discrete vessel model in the reduced adult head model, we have been able to test whether the results obtained in our primary model are challenged qualitatively by use of a more realistic but complex model. Figure 8 shows that the change in geometry imposed when going from the primary model to the reduced adult head has little effect on the qualitative nature of the results. Importantly this heatsink result is replicated if heat transfer by blood is accounted for using the discrete vessel description (Fig. 9). Again, relatively uniform and high temperatures within the deep brain are predicted and a large temperature gradient is present in the skull and cortex. The major difference between the predictions of the two thermal modeling techniques is that the smooth contours obtained for the heatsink model are replaced by contours that show local distortions due to the presence of discrete vessels.

The only simulation that resulted in significant reduction in deep brain temperature was that in which the core temperature 
was assumed to be lowered to $34^{\circ} \mathrm{C}$ (Fig. 10), implying the necessity to reduce systemic temperature to achieve deep brain cooling.

Because brain perfusion is so effective in conveying heat and keeping the deep brain at body temperature, vice-versa the body as a whole will be subjected to a significant heat drain from the cap. Through a drop in venous return temperature, head cooling will clearly lead to body cooling. The average temperature of blood leaving the head through the two main veins, as calculated in the discrete vessel model for CBF 30 $\mathrm{mL} \cdot \mathrm{min}^{-1} \cdot 100 \mathrm{~g}^{-1}$ and body temperature of $37^{\circ} \mathrm{C}$, was $34.2^{\circ} \mathrm{C}$. This corresponds to a $32-\mathrm{W}$ cooling rate for this cap. As in the simulations the body temperature is assumed to be controlled at a fixed temperature, this means that extra heating (or prevention of heat loss) equivalent to $32 \mathrm{~W}$ has to be provided.

Although the predictions described above have not been directly verified in this case, both thermal models used in this work have undergone previous verification in a number of applications (e.g. $(16,22,23)$. Furthermore, similar predictions to those reported here are described by Nelson and Nunnenly (24) who used a hemispherical tissue layered numerical model of the human head/brain. They also found that because of the low surface to volume ratio, low tissue thermal conductivity and high rate of cerebral perfusion, cerebral temperatures (except for the most superficial level of the cerebrum) were insensitive to surface conditions. Predominance of the thermal impact of blood supply over transcranial conductive cooling was also shown in numerical modeling of the brain during cold-water near-drowning (25).

Some data from animal studies that are consistent with the modeled results are available. Laptook et al. have used invasive temperature probes to determine the temperature profile within the piglet brain during both selective head and total body cooling. Their results show that the deep brain structures are closely linked to core body temperature and not greatly affected by selective head cooling (A. Laptook, Department of Pediatrics, University of Texas Southwestern Medical Center, Dallas, personal communication 1998).

In summary, the modeling results testify that the hypothesis that: cooling of the surface of the cranium by the application of a cooling bonnet significantly reduces deep brain temperature and produces a temperature differential between the deep brain and core body temperature is false. Only when the infant's core temperature is lowered can a significant reduction in deep brain temperature be achieved.

\section{REFERENCES}

1. Colbourne F, Corbett D 1995 Delayed postischemic hypothermia: a six month survival study using behavioral and histological assessments of neuroprotection. J Neurosci 15:7250-7260
2. Sirimanne E, Blumberg RM, Bossano D, Gunning M, Edwards AD, Gluckman PD, Williams CE 1996 The effect of prolonged modification of cerebral temperature on outcome following hypoxic-ischaemic brain injury in the infant rat. Pediatr Res 39:591-597

3. Thoresen M, Penrice J, Lorek A, Cady E, Wylezinska M, Kirkbride V, Cooper C, Brown GC, Edwards AD, Wyatt JS, Reynolds EOR 1995 Mild hypothermia following severe transient hypoxia-ischaemia ameliorates delayed cerebral energy failure in the newborn piglet. Pediatr Res 37:667-670

4. Gunn AJ, Gunn TR, de Haan HH, Williams CE, Gluckman PD 1997 Dramatic neuronal rescue with prolonged selective head cooling after ischemia in fetal lambs. J Clin Invest 99:248-256

5. Thoresen M, Satas S, Puka-Sundvall M, Whitelaw A, Hallestrom A, Loberg E, Ungerstedt U, Steen PA, Hagberg H 1997 Post-hypoxic hypothermia reduces cerebrocortical release of $\mathrm{NO}$ and excitotoxins. Neuroreport 8:3359-3362

6. Edwards AD, Yue X, Squier MV, Thoresen M, Cady EB, Penrice J, Cooper C, Wyatt JS, Reynolds EOR, Mehmet H 1995 Specific inhibition of apoptosis after cerebral hypoxia-ischaemia by moderate post-insult hypothermia. Biochem Biophys Res Commun 217:1193-1199

7. Gunn AJ, Gluckman PD, Gunn TR 1998 Selective head cooling in newborn infants after perinatal asphyxia: a safety study. Pediatrics 102:885-892

8. Azzopardi D, Cowan FM, Robertson NJ, Edwards AD 1999 Mild whole body hypothermia following birth asphyxia. Pediatr Res 45:908(abstr)

9. Cady EB, D'Souza PC, Penrice J, Lorek A 1995 The estimation of local brain temperature by in vivo $1 \mathrm{H}$ magnetic resonance spectroscopy Magn Reson Med 33:862-867

10. Mellergard P 1992 Changes in human intracerebral temperature in response to different methods of brain cooling. Neurosurgery 31:671-677

11. Rutherford MA, Pennock J, Counsell S, Mercuri E, Cowan F, Dubowitz L, Edwards AD 1998 Abnormal magnetic resonance signal in the internal capsule predicts poor neurodevelopmental outcome in infants with hypoxic-ischaemic encephalopathy. Pediatrics 102:323-328

12. Pennes HH 1948 Analysis of tissue and arterial blood temperature in the resting human forearm. J Appl Physiol 1:93-122

13. Van der Koijk JF, Lagendijk JJW, Crezee J, De Bree J, Kotte ANTJ, Van Leeuwen GMJ, Battermann JJ 1997 The influence of vasculature on temperature distributions in MECS interstitial hyperthermia: importance of longitudinal control. Int J Hyperther 13:365-385

14. Rawnsley RJ, Roemer RB, Dutton AW 1994 The simulation of discrete vessel effects in experimental hyperthermia. J Biomech Eng 116:256-262

15. Gagge AP, Nishi Y 1977 Heat exchange between human skin surface and thermal environment. In: D Lee (ed) Handbook of Physiology. Section 9: Reactions to Environmental Agents. American Physiological Society, Bethesda, pp 69-92

16. Van Leeuwen GMJ, Lagendijk JJW, Van Leersum BJAM, Zwamborn APM, Hornsleth SN, Kotte ANTJ 1999 Calculation of change in brain temperatures due to exposure to a mobile phone. Phys Med Biol 44:2367-2379

17. Van Leeuwen GMJ, Kotte ANTJ, Lagendijk JJW 1998 A flexible algorithm for construction of 3-D vessel networks for use in thermal modeling. IEEE Trans Biomed Eng 45:596-604

18. Kotte ANTJ, Van Leeuwen GMJ, De Bree J, Van der Koijk JF, Crezee J, Lagendijk JJW 1996 A description of discrete vessel segments in thermal modeling of tissues. Phys Med Biol 41:865-884

19. Kotte ANTJ, Van Leeuwen GMJ, Lagendijk JJW 1999 Modeling the thermal impact of a discrete vessel tree. Phys Med Biol 44:57-74

20. Van Leeuwen GMJ, Kotte ANTJ, Crezee J, Lagendijk JJW 1997 Tests of the geometrical description of blood vessels in a thermal model using counter-current geometries. Phys Med Biol 42:1515-1532

21. Weinbaum S, Jiji LM 1985 A new simplified bioheat equation for the effect of blood flow on local average tissue temperature. J Biomech Eng 107:131-139

22. Hand JW, Lau RW, Lagendijk JJW, Ling J, Burl M, and Young IR 1999 Electromagnetic and thermal modeling of SAR and temperature fields in tissue due to an RF decoupling coil. Magn Reson Med 42:183-192

23. Raaymakers BW, Crezee J, and Lagendijk JJW 1998 Comparison of temperature distributions in interstitial hyperthermia: experiments in bovine tongues versus generic simulations. Phys Med Biol 43:1199-1214

24. Nelson DA, and Nunneley SA 1998 Brain temperature and limits on transcranial cooling in humans: quantitative modeling results. Eur J Appl Physiol 78:353-359

25. Xu X, Tikuisis P, and Giesbrecht G 1999 A mathematical model for human brain cooling during cold-water near-drowning. J Appl Physiol 86:265-272 